\title{
Does Surgery Benefit Postmenopausal Overweight Women with Pelvic Floor Dysfunction?
}

\author{
Márta Hock ${ }^{*}$, Balázs Domány², József Bódis ${ }^{2,3}$, János Garai ${ }^{4}$ \\ ${ }^{1}$ Institute of Physiotherapy and Sport Sciences, Faculty of Health Sciences, University of Pécs, Pécs, Hungary \\ ${ }^{2}$ Department of Obstetrics and Gynaecology, Faculty of Medicine, University of Pécs, Pécs, Hungary \\ ${ }^{3}$ MTA-PTE Human Reproduction Scientific Research Group, Pécs, Hungary \\ ${ }^{4}$ Institute of Pathophysiology and Gerontology, Faculty of Medicine, University of Pécs, Pécs, Hungary \\ Email: ${ }^{*}$ hock.marta@etk.pte.hu
}

Received 21 June 2014; revised 24 July 2014; accepted 6 August 2014

Copyright (C) 2014 by authors and Scientific Research Publishing Inc.

This work is licensed under the Creative Commons Attribution International License (CC BY).

http://creativecommons.org/licenses/by/4.0/

(c) (i) Open Access

\section{Abstract}

Introduction: Pelvic floor muscle function of 30 overweight postmenopausal women prior to and after colporrhahpy was monitored in this study. Material and Methods: Patients diagnosed with cystokele or combined cysto-rectokele was involved. $1 \mathrm{mg}$ oral estriol and local estriol cream were administered for $\mathbf{3 0}$ days preoperatively. Pelvic floor muscle function was monitored by surface electromyography 1 month before (1st) 1 day prior to surgery (2nd), and six weeks after the surgery (3rd measurement). Body composition parameters (intra- and extracellular water and body fat) were also measured. Results: The ability to relax significantly improved $(p=0.03)$ in the preoperative period (between $1^{\text {st }}$ and $2^{\text {nd }}$ occasions). Six weeks after surgery a non-significant $(p=$ 0.054) decrease in average muscle activity was detected when compared with values obtained before the surgery. Muscle-activity declined significantly from the first to the last measurements $(p=$ 0.005). Conclusion: Our results confirm that postmenopausal obese women who undergo anterior or posterior colporrhaphy need a follow-up concerning pelvic floor muscle function and suggest that physiotherapy started the earliest possible may aid in preserving postoperative functionality on the long run.

\section{Keywords}

Pelvic Floor Muscle Function, Operative Period, Body Composition, Postmenopause, Obesity

\footnotetext{
${ }^{*}$ Corresponding author.
} 


\section{Introduction}

Proper support of pelvic organs is maintained by the intact and coordinated functioning of pelvic floor muscles, their innervations and the connective tissue elements [1]. Increased weight (e.g. in obesity or due to internal organ enlargements) or abnormal power impulses (increased intraabdominal pressure) might overload and injure connective tissues as well as pelvic floor muscles (PFM) that leads to pelvic floor dysfunction, and eventually to pelvic organ prolapse [2]-[5].

Interventions mainly aim to reconstitute connective tissue [6] [7]. Isolated insufficiency of single pelvic tissues, however, is rare. This may explain why surgical management of pelvic organ prolapse proves unsuccessful in about one third of the cases [8].

In 2005 Vakili et al. established that the more preoperative muscle strength the women had, the higher chance they had to avoid relapse or reoperation [9]. To our knowledge, no study has reported yet the outcome of surgery against pelvic organ prolapse in relation to the pelvic floor muscle function of the preoperative period. In our follow-up study, we have aimed to correlate the preoperative pelvic floor muscle function with the surgical outcome in high risk and overweight patients.

\section{Materials and Methods}

Volunteers were recruited from patients with pelvic floor dysfunction who attended the Department of Obstetrics and Gynaecology and the Institute of Physiotherapy and Nutritional Sciences of the University of Pécs, starting in 2010 for two consecutive years. The research protocol was approved by the Regional Research Ethics Committee of the University of Pécs (Reg. Nr: 2490). The volunteers signed an informed consent on anonymous statistical analysis of their health-related and anthropometric data. Inclusion criteria were established cystokele or combined cysto-rectokele diagnosis of the patients. The study involved 30 postmenopausal, Caucasian women who underwent anterior colporrhaphy or colpoperineorrhaphy. Exclusion criteria were as follows: use of complementary medicines or special diet (e.g. slimming course or preference of phytoestrogen rich foods), pelvic floor muscle exercises, lack of cooperation, existence of psychiatric disorders, sleep disorders, clinically relevant laboratory abnormalities (e.g. liver and kidney function), acute or chronic systemic diseases (fever, confirmed infection, autoimmune diseases, neoplasm, etc.), severe neurological disease in medical history (damage to the N. pudendus, spina bifida, multiple sclerosis, progressive muscle dystrophy etc.).

At the first session a thorough medical history was taken about the volunteers' general medical condition, previous operations and interventions, gynaecological complaints and regular medications. To assess symptoms affecting the volunteers' quality of life we used the Menopause Rating Scale (MRS) [10]. Participants’ abdominal muscle condition was assessed with the help of Eurofit test. The Body Mass Index (BMI) and the waist-hip ratio have been calculated as well.

During the perioperative period body composition was monitored with HUMAN IM-SCAN Bioelectrical Impedance Analyser from Dietosystem, Milan, Italy with the software Master 1.0. Measurements were performed one month and one day prior to surgery, then on the 1st and 42nd postoperative days (6th postoperative week). The following parameters were computed: Total Body Water (TBW), Extracellular Water (EW) and Intracellular water (IW), Fat Mass (FM) as well as Fat Free Mass (FFM).

Pelvic floor muscle activity was assessed with FemiScan surface EMG (Mega Electronics Ltd, Kuopio, Finland). The following parameters were measured: muscle activity, relaxing ability and activity differences between the left- and right sides. Measurements were performed 1 month and 1 day prior to surgery, and on the 6th postoperative week. Preoperative management involved daily $1 \mathrm{mg}$ oral estriol (Ovestin tablet) and local hormone therapy (Ovestin cream, $1 \mathrm{mg} / \mathrm{g}$ estriol). No other special care was provided during the pre- or postoperative periods, neither any specific pelvic floor muscle exercises were performed prior to or during the study.

The statistical data were processed according to mean, standard deviation, median, range. Data obtained before and after the surgery were compared by Fisher's exact test or Student's t-test, and the results were considered to be significant at $\mathrm{p}<0.05$.

\section{Results}

Demographic data of participant postmenopausal (59.47 \pm 8.58 years) women (BMI $30.3 \pm 3.86$ kg/m²; median: $29.6 \mathrm{~kg} / \mathrm{m}^{2}$ ), the waist circumference mean and waist-hip ratioare listed in Table 1 . Average pregnancy rate was 3.5 ( \pm 1.59$)$, number of births was $2.43( \pm 1.41)$ and birth weights were $3295.16 \pm 352.58 \mathrm{~g}$ (range $2600-4100 \mathrm{~g})$. 
In previous medical history of the participants the following surgical events have been recorded: colpoperineorrhaphy in 6 cases, adnexectomy in 5 cases, myoma removal in 2 cases and two vaginal hysterectomies one without- and the other one with bilateral oophorectomy. Of non-gynecological surgeries (e.g. appendectomy, herniotomy, mastectomy and cholecystectomy etc.) 8 were performed. Concomitant diseases are listed in Table 1.

Initial urogenital dimension of the Menopause Rating Scale decreased by 0.36 points at the end of examination. Detailed MRS results are listed in Table 1. According to Eurofit tests the patients achieved 58\% less than expectable abdominal strength.

Most of the participants (except 2 of them; 93.33\%) were regularly involved in some kind of physical work (e.g. moving goods or gardening) due to their jobs and/or their hobbies.

No significant difference was observed in body composition (Table 2) between the first and second sessions in the preoperative period. There was no difference in the average fluid intake (1.73 $\pm 0.39 \mathrm{l} /$ day), and eating habits between pre- and postoperative periods. Concerning bioelectrical impedance data of the second and third sessions (i.e. immediate pre- and postoperative days) a significant difference was found in each computed parameters, except the intracellular fluid $(\mathrm{p}=0.15)$. Fluid replacement during surgery and the postoperative period followed the regular management of 1st degree postoperative care. No significant changes were found between bioelectrical impedance data obtained on the 1st postoperative day and 6 weeks after the surgery (Table 3 ).

Table 1. Descriptive characteristic of patients.

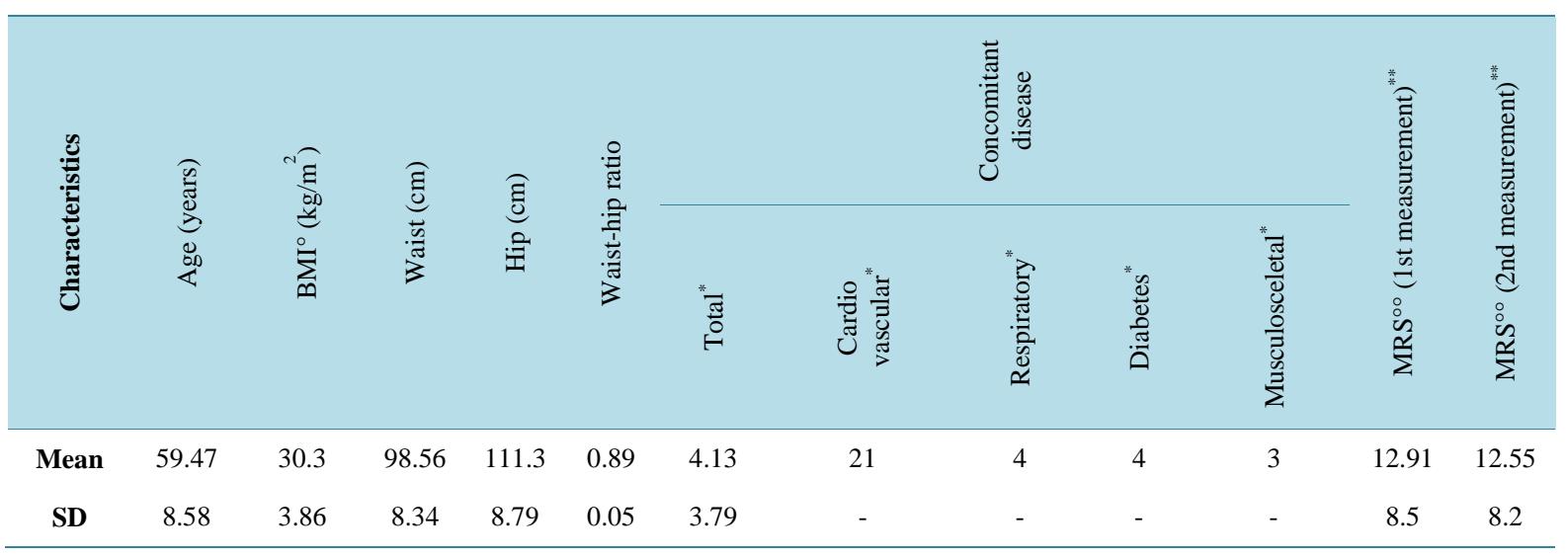

${ }^{*}$ counts; ${ }^{* *}$ scores; ${ }^{\circ}$ Body Mass Index (BMI); ${ }^{\circ}$ Menopause Rating Scale (MRS).

Table 2. Data of total body fat and pelvic floor muscle (PFM) strength.

\begin{tabular}{|c|c|c|c|c|c|c|c|c|c|c|c|c|}
\hline \multirow{3}{*}{ 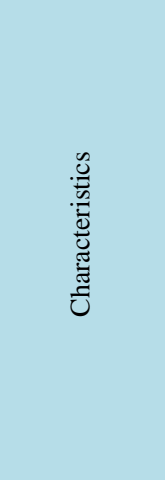 } & \multicolumn{3}{|c|}{ 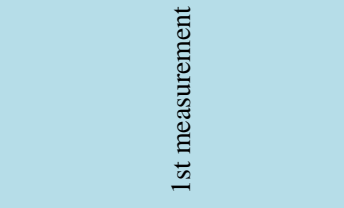 } & \multicolumn{3}{|c|}{ 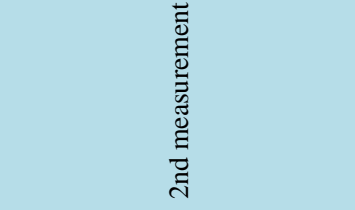 } & \multicolumn{3}{|c|}{ 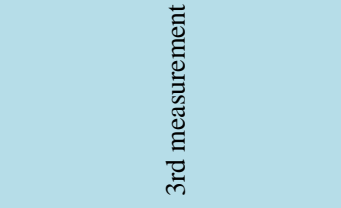 } & \multicolumn{3}{|c|}{ 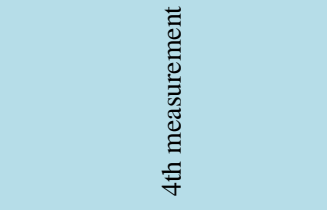 } \\
\hline & \multirow{2}{*}{$\begin{array}{l}\text { In } \\
\text { +1 } \\
\text { च } \\
\stackrel{\Xi}{\Sigma}\end{array}$} & \multicolumn{2}{|c|}{$\begin{array}{l}\text { Uे } \\
\text { ㅇํㅁ }\end{array}$} & \multirow{2}{*}{$\begin{array}{l}\text { 더 } \\
+1 \\
+1 \\
\text { ॠ } \\
\stackrel{\Xi}{\Sigma}\end{array}$} & \multicolumn{2}{|c|}{$\begin{array}{l}\text { Uे } \\
\text { ㅇํ }\end{array}$} & \multirow{2}{*}{ 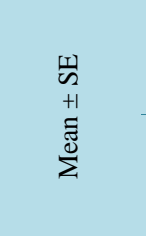 } & \multicolumn{2}{|c|}{$\begin{array}{l}\text { Uे } \\
\text { ओั }\end{array}$} & \multirow{2}{*}{ 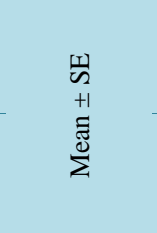 } & \multicolumn{2}{|c|}{$\begin{array}{l}\text { Uे } \\
\text { ओัे }\end{array}$} \\
\hline & & $\begin{array}{l}\dot{0} \\
\text { ż } \\
0\end{array}$ & 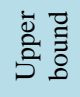 & & 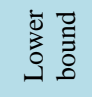 & 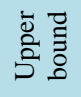 & & 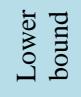 & 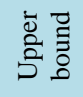 & & 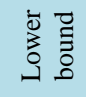 & 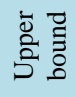 \\
\hline $\begin{array}{c}\text { Total } \\
\text { body fat (\%) }\end{array}$ & $30.13 \pm 3.1$ & 25.03 & 35.23 & $27.92 \pm 3.16$ & 22.76 & 33.08 & $28.3 \pm 3.23$ & 23.05 & 33.56 & $28.33 \pm 3.25$ & 21.96 & 34.71 \\
\hline $\begin{array}{c}\text { PFM }^{*} \\
\text { strength }(\mu \mathrm{V})\end{array}$ & $7.13 \pm 0.97$ & 5.23 & 9.04 & $6.98 \pm 1.206$ & 4.62 & 9.35 & - & - & - & $5.55 \pm 0.76$ & 3.83 & 7.27 \\
\hline
\end{tabular}

*Pelvic Floor Muscle (PFM) Strength. 
Table 3. p value of body composition parameters.

\begin{tabular}{|c|c|c|c|c|c|}
\hline Measurements & $\mathrm{TBW}^{*}$ & $\mathrm{ECW}^{* *}$ & $\mathrm{ICW}^{* * *}$ & $\mathrm{FM}^{* * * *}$ & $\mathrm{FFM}^{* * * * *}$ \\
\hline 1st and 2nd measurements & 0.76 & 0.75 & 0.35 & 0.99 & 0.99 \\
\hline 2nd and 3rd measurements & 0.043 & 0.031 & 0.15 & 0.023 & 0.023 \\
\hline 3rd and 4th measurements & 0.83 & 0.61 & 0.81 & 0.5 & 0.3 \\
\hline
\end{tabular}

${ }^{*}$ Total Body Water (TBW), ${ }^{* *}$ Extracellular Water (EW), ${ }^{* * *}$ Intracellular water (IW), ${ }^{* * * *}$ Fat Mass (FM), ${ }^{* * * * *}$ Fat Free Mass (FFM).

Surface EMG results show a significant improvement in the pelvic floor muscles' ability to relax $(p=0.03)$ in the preoperative period (1st and 2nd sessions). Although not significant $(p=0.054)$, but a decreasing tendency was observed in average muscle strength on the day before and at 6 weeks after the surgery, a significant decrease of muscle strength was found at the left side $(p=0.034)$. A significant $(p=0.005)$ decrease was found between the first and last sessions' (1 month prior the surgery and 6 weeks after surgery) average muscle strength.

\section{Discussion}

Obesity is a common condition among people nowadays that may significantly contribute to pelvic organ prolapse. Other well known risk factors are: increased intraabdominal pressure, advanced age, previous local surgical interventions and weakness of levator muscle function [11]-[16]. Body mass index of all our obese patients reached or exceeded the upper limit of 25 in the follow-up period, a factor that is known to contribute to postoperative relapses [17]. According to the waist-hip ratio central obesity is prevalent in our sample which is an increased risk factor for prolapse [18]. A higher than average FM was observed already in the preoperative period, despite the fact, that almost all participants (93.3\%) performed regular physical activity in their jobs and /or free time, but it decreased by 1.8 FM\% (5.97\%) during the postoperative follow-up.

It is widely accepted that levator muscle function is a determinant for not only the subjective or objective symptoms but also for relapse and for a need of a surgical intervention in pelvic floor dysfunction. The anatomical position of the levator muscle may favourably change in the postoperative period [4] [9]. In current study pelvic floor muscle activity indicators showed poor results in the preoperative period. When compared with data of Rett et al. who found $20.9( \pm 2.7) \mu \mathrm{V}$ average muscle activity, our values were $65.88 \%$ lower [19]. It might be due to the aging process where not only skeletal muscle weakness but also a decrease in both the connective tissue and the smooth muscle fiber strength [20] may occur in the urethral sphincter. The subjects in our study were about 17 years older [19]. Dannecker et al. found a 36.9\% better result in pelvic floor muscle activity in their group, where average age was approximately the same [21]. The difference may be due to the $17.49 \%$ lower average BMI of their patients. Nevertheless, the type of obesity was not clarified in these previous studies. Our group involved patients suffering particularly from abdominal obesity. It may result in pelvic floor weakness and abdominal muscle dysfunction leading to disturbance of the biomechanical balance between abdominal and pelvic floor muscles [22].

Lack of hormonal effect in postmenopausal women changes the tissue quality in the levator muscle and sacrouterine ligaments [23]-[28]. Muscle activity results on the preoperative day and 6 weeks after the surgery show a significant decrease. Muscular activity difference found between the right and left sides might most probably explained by scar of the episiotomic incision generally performed on the right side in Hungary.

Taking into consideration the average muscle activity of the pelvic floor as measured by the EMG a significant, 22.15\% decreasing tendency can be seen 1 month prior the surgery and 6 weeks after surgery.

Our knowledge on the origin and therapy of pelvic floor muscle dysfunctions is still insufficient. A higher case number from randomized sample would be needed in the future to obtain more reliable data concerning pelvic floor dysfunction. Nevertheless, our study provides evidence that peri-operative physiotherapy improves physical outcomes and quality of life in women undergoing corrective surgery for urinary incontinence and/or pelvic organ prolapse [29]. The main strength of the study is its scope since only scarce reports are found to date in the literature on studies that addressed the change of pelvic muscle strength before and after the appropriate gynecological surgeries. Limitations of our study are the relative low number of participants, the non-randomised, non-double-blind setting and the short follow-up period. Further studies would be necessary to compare a control group and a group performing pelvic floor muscle training as well. 


\section{Conclusion}

Our results confirm that postmenopausal obese women who undergo anterior or posterior colporrhaphy need a follow-up concerning pelvic floor muscle function and suggest that physiotherapy starting the earliest possible may aid in preserving postoperative functionality on the long run.

\section{Acknowledgements}

This study was supported by SROP-4.2.2.A-11/1/KONV-2012-0053 Investigation of biomarkers in culture medium for the success rate of in vitro fertilization and PTE AOK KA 2013/10.

\section{References}

[1] Wei, J. and De Lancey, J.O.L. (2004) Functional Anatomy of the Pelvic Floor and Lower Urinary Tract. Clinical Obstetrics and Gynecology, 47, 3-17. http://dx.doi.org/10.1097/00003081-200403000-00004

[2] Brown, J., Grady, D., Ouslander, J., et al. (1999) Prevalence of Urinary Incontinence and Associated Risk Factors in Postmenopausal Women: Heart and Estrogen/Progestin Replacement Study (HERS) Research Group. Obstetrics Gynecology, 94, 66-70. http://dx.doi.org/10.1016/S0029-7844(99)00263-X

[3] Lambert, D.M., Marceau, S. and Forse, R.A. (2005) Intraabdominal Pressure in the Morbidly Obese. Obesity Surgery, 15, 1225-1232. http://dx.doi.org/10.1381/096089205774512546

[4] Song, Y., Ye, P., Hong, X., et al. (2009) Changes in Levatorani Muscle after Vaginal Hysterectomy and Prolapse Repair Using the Total Prolift Procedure. International Journal of Gynecology and Obstetrics, 106, 53-56. http://dx.doi.org/10.1016/j.ijgo.2009.03.007

[5] Chen, L., Ashton-Miller, J.A., Hsu, Y., et al. (2006) Interaction among Apical Support, Levatorani Impairment, and Anterior Vaginal Wall Prolapse. Obstetrics Gynecology, 108, 324-332. http://dx.doi.org/10.1097/01.AOG.0000227786.69257.a8

[6] Grody, M.H. (2003) Posterior Compartment Defects. In: Rock, J.A. and Jones, H.W., Eds., Telinde’s Operative Gynecology, Lippincott Williams \&Wilkins, Philadelphia, 966-985.

[7] Richardson, A.C. (1993) Therectovaginal Septum Revisited: Its Relationship and Its Importance in Rectocoele Repair. Clinical Obstetrics and Gynecology, 36, 976-983. http://dx.doi.org/10.1097/00003081-199312000-00022

[8] Olsen, A.L., Smith, V.J., Bergstrom, J.O., et al. (1997) Epidemiology of Surgically Managed Pelvic Organ Prolapse and Urinary Incontinence. Obstetrics Gynecology, 89, 501-506. http://dx.doi.org/10.1016/S0029-7844(97)00058-6

[9] Vakili, B., Zehg, Y.T., Loesch, H., et al. (2005) Levator Contraction Strength and Genital Hiatus as Risk Factors for Recurrent Pelvic Organ Prolapse. American Journal of Obstetrics Gynecology, 192, 1592-1598. http://dx.doi.org/10.1016/j.ajog.2004.11.022

[10] Schneider, H.P.G., Heinemann, L.A.J., Rosemeier, H.P., Potthoff, P. and Behre, H.M. (2000) The Menopause Rating Scale (MRS): Reliability of Scores of Menopausal Complaints. Climacteric, 3, 59-64. http://dx.doi.org/10.3109/13697130009167600

[11] Wasserberg, N., Petrone, P., Haney, M., et al. (2009) Effect of Surgically Induced Weight Loss on Pelvic Floor Disorders in Morbidly Obese Women. Annals of Surgery, 249, 72-76. http://dx.doi.org/10.1097/SLA.0b013e31818c7082

[12] Starczewski, A., Brodowska, A. and Brodowski, J. (2008) Epidemiology and Treatment for Urinary Incontinence and Pelvic Organ Prolapse in Women. Polski Merkuriusz Lekarski, 25, 74-76.

[13] Wagg, A., Potter, J., Peel, P., et al. (2008) National Audit of Continence Care for Older People: Management of Urinary Incontinence. Age and Ageing, 37, 39-44. http://dx.doi.org/10.1093/ageing/afm163

[14] Subak, L.L., Waetjen, L.E., van den Eeden, S., et al. (2001) Cost of Pelvic Organ Prolapse Surgery in the United States. Obstetrics Gynecology, 98, 646-651. http://dx.doi.org/10.1016/S0029-7844(01)01472-7

[15] Hollabaugh Jr., R.S., Dmochowski, R.R., Kneib, T.G., et al. (1998) Preservation of Putative Continence Nerves during Radical Retropubic Prostatectomy Leads to More Rapid Return of Urinary Continence. Urology, 51, 960-967. http://dx.doi.org/10.1016/S0090-4295(98)00128-9

[16] Guri, R., Jeanette, S.B., David, H.T., et al. (2007) Symptomatic Pelvic Organ Prolapse: Prevalence and Risk Factors in a Population-Based, Racially Diverse Cohort. Obstetrics Gynecology, 109, 1396-1403. http://dx.doi.org/10.1097/01.AOG.0000263469.68106.90

[17] Moalli, P.A., Jones, I.S., Meyn, L.A., et al. (2003) Risk Factors Associated with Pelvic Floor Disorders in Women Undergoing Surgical Repair. Obstetrics Gynecology, 101, 869-874. http://dx.doi.org/10.1016/S0029-7844(03)00078-4

[18] Brown, J., Grady, D., Ouslander, J., et al. (1999) Prevalence of Urinary Incontinence and Associated Risk Factors in 
Postmenopausal Women: Heart and Estrogen/Progestin Replacement Study (HERS) Research Group. Obstetrics Gynecology, 94, 66-70. http://dx.doi.org/10.1016/S0029-7844(99)00263-X

[19] Perucchini, D., De Lancey, J.O.L. and Blaivas, M. (1997) Evidence of Major Myopathic Changes in the Striated Urethral Sphincter Muscle in the Female. Neurourology and Urodynamics, 15, 394-395.

[20] Rett, M.T., Simoes, J.A., Herrmann, V., et al. (2007) Management of Stress Urinary Incontinence with Surface Electromyography-Assisted Biofeedback in Women of Reproductive Age. Physical Therapy, 87, 136-142. http://dx.doi.org/10.2522/ptj.20050318

[21] Dannecker, C., Wolf, V., Raab, R., et al. (2005) EMG-Biofeedback Assisted Pelvic Floor Muscle Training Is an Effective Therapy of Stress Urinary or Mixed Incontinence: A 7-Year Experience with 390 Patients. Archives of Gynecology and Obstetrics, 273, 93-97. http://dx.doi.org/10.1007/s00404-005-0011-4

[22] Madill, S.J., Harvey, M.A. and McLean, L. (2009) Women with SUI Demonstrate Motor Control Differences during Voluntary Pelvic Floor Muscle Contractions. International Urogynecology Journal, 20, 447-459.

[23] Mokrzycki, M.L., Mittal, K., Smilen, S.W., et al. (1997) Estrogen and Progesterone Receptors in the Uterosacral Ligament. Obstetrics Gynecology, 90, 402-404. http://dx.doi.org/10.1016/S0029-7844(97)00285-8

[24] Hodgins, M.B., Spike, R.C., Mackie, R.M., et al. (1998) An Immunohistochemical Study of Androgen, Oestrogen and Progesterone Receptors in the Vulva and Vagina. British Journal of Obstetrics and Gynaecology, 105, 216-222. http://dx.doi.org/10.1111/j.1471-0528.1998.tb10056.x

[25] Smith, P., Heimer, G., Norgren, A., et al. (1993) Localization of Steroid Hormone Receptors in the Pelvic Muscles. European Journal of Obstetrics, Gynecology, and Reproductive Biology, 50, 83-85. http://dx.doi.org/10.1016/0028-2243(93)90169-D

[26] Chen, G.D., Oliver, R.H., Leung, B.S., et al. (1999) Estrogen Receptor Alpha and Beta Expression in the Vaginal Walls and Uterosacral Ligaments of Premenopausal and Postmenopausal Women. Fertility and Sterility, 71, 10991102. http://dx.doi.org/10.1016/S0015-0282(99)00113-2

[27] Moalli, P.A., Klingensmith, W.L., Meyn, L.A., et al. (2002) Regulation of Matrix Metalloproteinase Expression by Estrogen in Fibroblasts That Are Derived from the Pelvic Floor. American Journal of Obstetrics Gynecology, 187, 72-79. http://dx.doi.org/10.1067/mob.2002.124845

[28] Gebhart, J.B., Rickard, D.J., Barrett, T., et al. (2001) Expression of Estrogen Receptor Isoforms $\alpha$ and $\beta$ Messenger RNA in Vaginal Tissue of Premenopausal and Postmenopausal Women. American Journal of Obstetrics Gynecology, 185, 1325-1331. http://dx.doi.org/10.1067/mob.2001.119627

[29] Jarvis, S.K., Hallam, T.K., Lujicm, S., et al. (2005) Peri-Operative Physiotherapy Improves Outcomes for Women Undergoing Incontinence and or Prolapse Surgery: Results of a Randomised Controlled Trial. Australian and New Zealand Journal of Obstetrics and Gynaecology, 45, 300-303. http://dx.doi.org/10.1111/j.1479-828X.2005.00415.X 
Scientific Research Publishing (SCIRP) is one of the largest Open Access journal publishers. It is currently publishing more than 200 open access, online, peer-reviewed journals covering a wide range of academic disciplines. SCIRP serves the worldwide academic communities and contributes to the progress and application of science with its publication.

Other selected journals from SCIRP are listed as below. Submit your manuscript to us via either submit@scirp.org or Online Submission Portal.
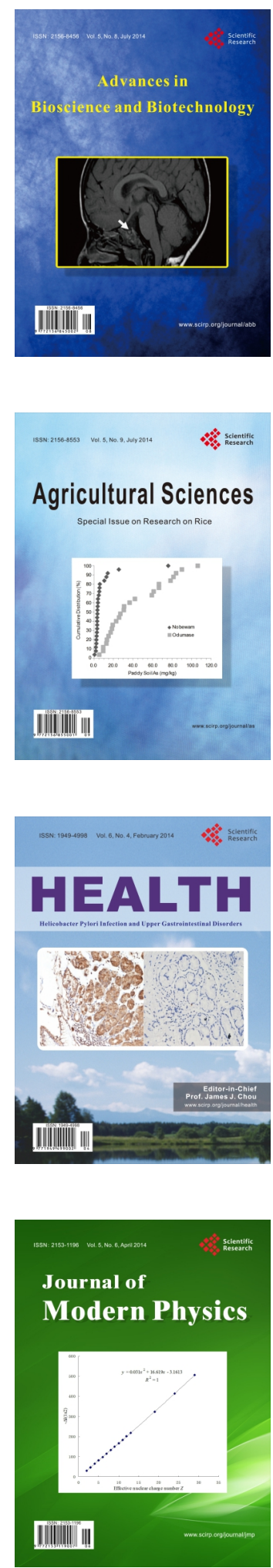
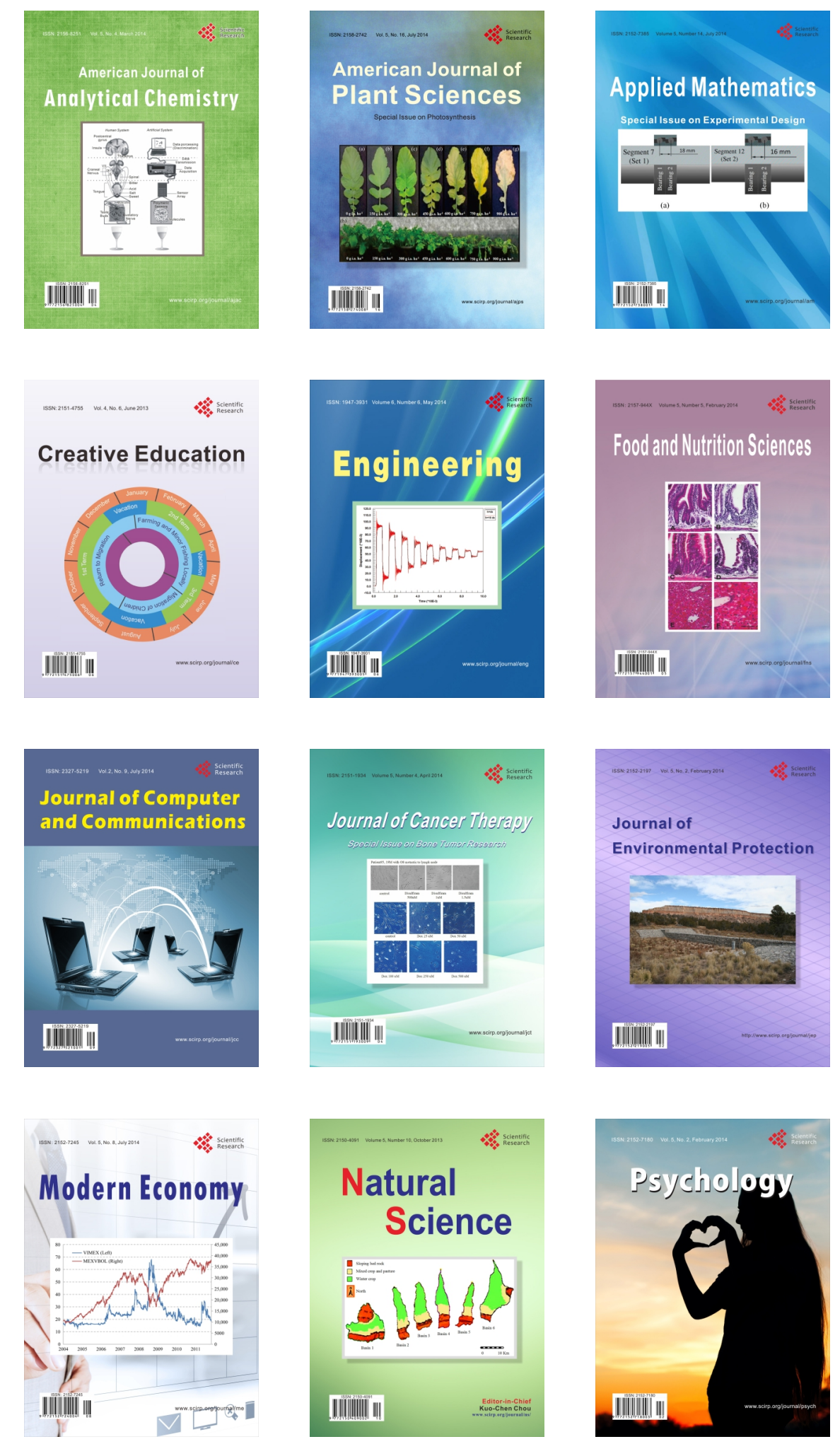